\title{
Women, patients with severe asthma, and patients attended by primary care physicians, are at higher risk of suffering from poorly controlled asthma
}

\author{
*Carlos Badiola ${ }^{a}$, Llorenc Badiellab, Vicente Plazac, Luis Prietod, Jesús Molina ${ }^{e}$, \\ José Ramón Villaf, Enrique Cimas ${ }^{\mathrm{f}}$
}

a GlaxoSmithKline S.A Medical Department, Tres Cantos, Madrid 28760, Spain

b Universidad Autónoma Barcelona - Statistics, Barcelona, Spain

Hospital Santa Creu i Sant Pau - Pneumology, Barcelona, Spain

d Hospital Dr. Peset - Allergy, Valencia, Spain

e Centro Salud Francia - Primary Care, Madrid, Spain

Hospital Niño Jesús - Paediatric Pneumology, Madrid, Spain

$g$ Centro Salud Contrueces - Primary Care, Asturias, Spain

Originally submitted 5th September 2008; resubmitted 13th December 2008; revised version received 9th January 2009; accepted 31st January 2009; online 26th June 2009

\begin{abstract}
Aim: The aim of this exploratory study was to identify those factors associated with asthma control assessed according to GINA Guidelines.

Method: 809 (56\% female) subjects with asthma were recruited consecutively from both specialist and primary care centres. Asthma control was assessed over a 4-week follow-up period using a composite measure. A multivariate analysis was performed, in which asthma control was included as the dependent variable and several explanatory variables were included as independent variables.

Results: Analysis performed on the whole population rendered gender $(p=0.003)$, the type of physician $(p<0.001)$, and age group $(p<0.001)$, as significant factors associated with asthma control. In adults, gender $(p=0.001)$, asthma severity $(p<0.001)$, and type of physician $(p<0.001)$ were significant, and only asthma severity was significant $(p=0.043)$ in children.

Conclusions: After model adjustment, we suggest that being female, suffering from more severe asthma, or being attended by a primary care physician, could pose a significantly higher risk of having poorly controlled asthma in adults.

(C) 2009 General Practice Airways Group. All rights reserved.

C Badiola et al. Prim Care Resp J 2009; 18(X): 294-299

doi:10.4104/pcrj.2009.00027
\end{abstract}

Keywords asthma, asthma control, adult asthma, paediatric asthma, women, primary care

\section{Introduction}

Asthma control has been an important topic for debate over the last few years, not only in terms of whether it is achievable in real practice, but also in terms of how to measure it. Since 2006, the Global Initiative for Asthma (GINA) has addressed this issue and provided clear recommendations about the measurement of asthma control.' In this regard, asthma control, as recommended by GINA, should be based on assessment of the following parameters: daytime and nocturnal symptoms; need for rescue medication; lung function; exacerbations; and limitation of activities.

Several studies - which assessed asthma control via patient surveys - have previously reported that objectives of asthma management were not being accomplished in a high proportion of patients., ${ }^{2,3}$ In 2005, a descriptive and prospective study described the level of asthma control in Spain when a guideline-defined asthma control composite measure was used. ${ }^{4}$ In this paper, we have conducted a post

* Corresponding author: Dr Carlos Badiola, Laboratorios Leti S.L.U. Departamento Médico, c/ del Sol, 5, Tres Cantos, Madrid 28760, Spain. Tel: +34 918037472 Fax: +34 917711795 E-mail: cbadiola@leti.com 
Figure 1. Scheme of the study design.

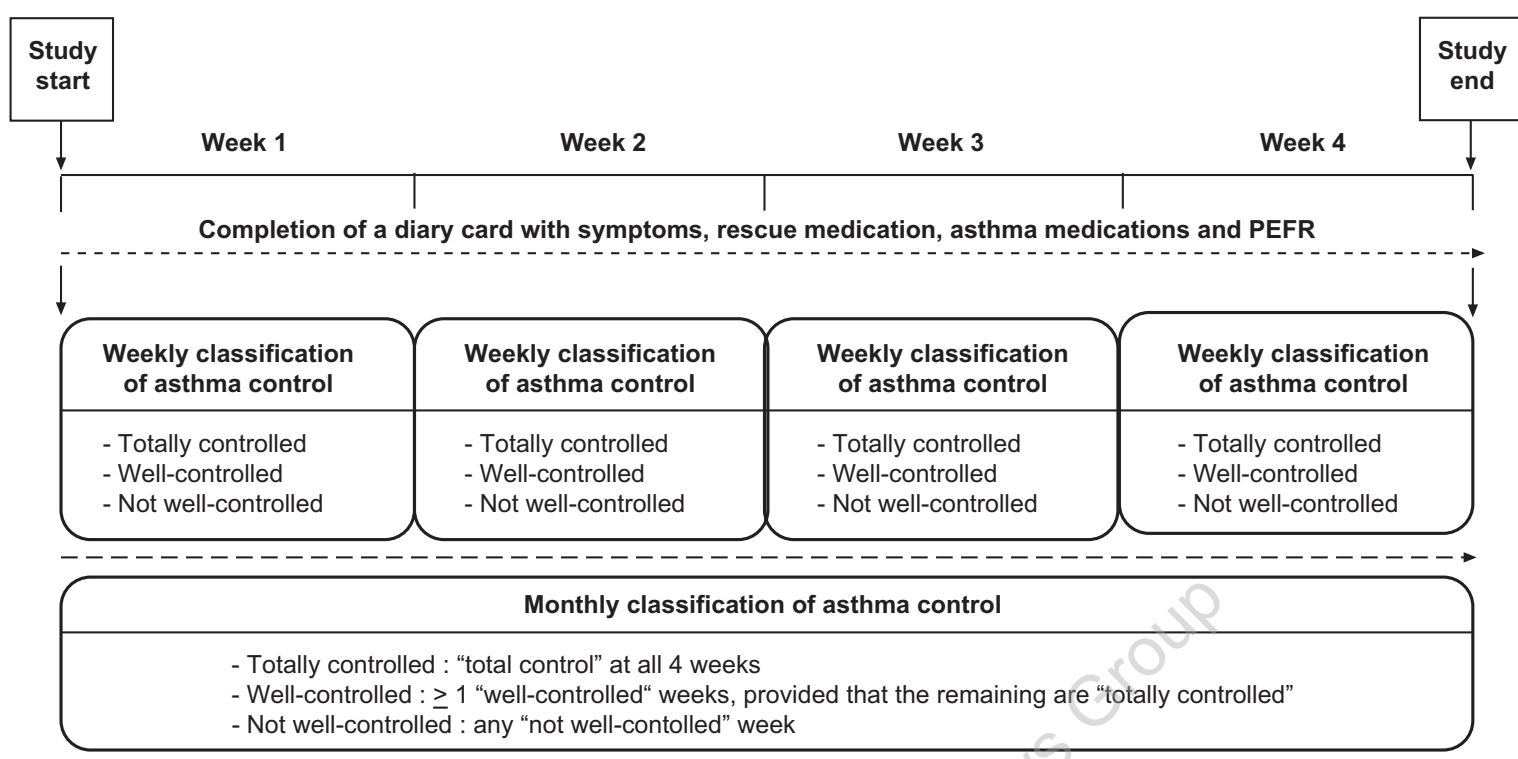

hoc multivariate exploratory analysis in order to gain some insight on those factors that could explain asthma control.

\section{Material and methods}

Material and methods have been described previously. ${ }^{4}$ Briefly, both adults and children were consecutively recruited from 30 specialist and 96 primary care sites and were followed-up for four weeks. Patients were eligible if they had previously been diagnosed of asthma and were capable of completing the diary card and using the peak expiratory flow (PEF) recorder adequately. Diagnosis of asthma was based on the fulfilment of at least two of the three following criteria: symptoms of asthma; reversible airflow obstruction (improvement $\geq 12 \%$ [and $200 \mathrm{~mL}$ only for adults] in $\mathrm{FEV}_{1}$ after administration of a short-acting $\beta_{2}$-agonist); and bronchial hyper-responsiveness to bronchoconstricting agents. Patients who had an asthma exacerbation, had received oral or parenteral corticosteroids, or had been admitted to hospital three months prior to the study start, were excluded. Patients were required to register daily in a diary card their asthma symptoms, rescue medication use, asthma medications received and the highest value of three morning PEF recordings during the 4-week follow-up period. Asthma control was assessed over the 4-week follow-up period. Every week was classified as "totally controlled", "well-controlled" or "not well-controlled" (if neither of both previous definitions were fulfilled), following similar criteria to the GOAL study. ${ }^{5}$ The 4-week follow-up period was classified as "totally controlled" only if "total control" was achieved during all four weeks. It was classified as "well-controlled" if one or more weeks were classified as "well-controlled" provided that the remaining weeks were classified as "totally controlled". If any week of the follow-up period was classified as "not well-controlled", it was considered as "not wellcontrolled". If there were not sufficient data to classify asthma control in any of the previously mentioned categories, it was considered as "non-evaluable". The study design is shown in Figure 1.

The following explanatory variables were registered: patients' gender; age (adults or children); race; asthma severity (intermittent, mild, moderate, or severe persistent); educational level (illiterate, primary or secondary education, degree, bachelor's degree); tobacco consumption (never smoker, exsmoker, active or passive smoker); time from asthma diagnosis (years); and type of physician (specialist or primary care). The patient's asthma severity was classified according to international guidelines. Patients were considered active smokers if they had smoked at least 100 cigarettes and they smoked all or some days at the time of the study assessment. Patients were considered ex-smokers if they had given up smoking at least six months before being enrolled.

\section{Statistical analysis}

A multivariate analysis was performed. Patients' real status of asthma control over the follow-up period was included as the dependent variable in the model. Patients' gender, age, race, asthma severity, educational level, tobacco consumption, time from asthma diagnosis, and type of physician, were all considered as independent variables in the model. Analysis was performed using SAS System software, v 9.1.3, SAS Institute Inc., Cary, NC, USA. For all statistical decisions a significance level of 0.05 has been used. Given the exploratory objective of the analysis, multiple comparisons 
correction has not been applied.

Categories of qualitative variables with observed frequencies less than $5 \%$ of the total study sample size have been grouped together with the nearest category in order to increase model sensitivity. Study population is described using relative and absolute frequencies for categorical variables, and mean and standard deviation for quantitative variables. The summary statistics are presented for the whole population and for asthma control groups.

The main analysis was performed in order to assess the relationship between independent variables and asthma control when the latter was classified into three possible categories - "not well-controlled", "well-controlled" and "totally controlled". A multiple nominal logistic regression model was applied in order to detect those variables which had influence on asthma control.

Another complementary analysis was conducted in order to improve the interpretation of the main analysis due to the interactions observed between some independent variables with age group. A multiple nominal logistic regression model stratified by age group was conducted.

The results of applying these models have been presented using Type III Tests of Fixed Effects. For the last analysis, modeladjusted probabilities for each level of explanatory variables are presented. These probabilities (model LSMEANS expressed as probabilities) show the predicted proportion of events

Table 1. Baseline characteristics of the analysis population.

\begin{tabular}{|c|c|c|c|c|c|c|c|c|c|c|}
\hline \multirow[t]{2}{*}{ Variables } & \multicolumn{2}{|c|}{ All } & \multicolumn{2}{|c|}{$\begin{array}{c}\text { Non- } \\
\text { evaluable }\end{array}$} & \multicolumn{2}{|c|}{$\begin{array}{c}\text { Not } \\
\text { well-controlled }\end{array}$} & \multicolumn{2}{|c|}{$\begin{array}{l}\text { Well- } \\
\text { controlled }\end{array}$} & \multicolumn{2}{|c|}{$\begin{array}{c}\text { Totally } \\
\text { controlled }\end{array}$} \\
\hline & $\mathrm{N}$ & $\%$ & $\mathrm{~N}$ & $\%$ & $\mathrm{~N}$ & $\%$ & $\mathrm{~N}$ & $\%$ & $\mathrm{~N}$ & $\%$ \\
\hline \multicolumn{11}{|l|}{ Gender } \\
\hline Males & 356 & 44.0 & 19 & 5.3 & 203 & 57.0 & 99 & 27.8 & 35 & 9.8 \\
\hline Females & 453 & 56.0 & 29 & 6.4 & 311 & 68.7 & 92 & 20.3 & 21 & 4.6 \\
\hline \multicolumn{11}{|l|}{ Educational level } \\
\hline Illiterate / Primary & 369 & 45.6 & 18 & 4.9 & 244 & 66.1 & 79 & 21.4 & 28 & 7.6 \\
\hline Secondary & 300 & 37.1 & 20 & 6.7 & 190 & 63.3 & 71 & 23.7 & 19 & 6.3 \\
\hline Degree & 65 & 8.0 & 5 & 7.7 & 39 & 60.0 & 18 & 27.7 & 3 & 4.6 \\
\hline Bachelor's degree & 75 & 9.3 & 5 & 6.7 & 41 & 54.7 & 23 & 30.7 & 6 & 8.0 \\
\hline \multicolumn{11}{|l|}{ Age group } \\
\hline Adults & 641 & 79.2 & 39 & 6.1 & 427 & 66.6 & 147 & 22.9 & 28 & 4.4 \\
\hline Children & 168 & 20.8 & 9 & 5.4 & 87 & 51.8 & 44 & 26.2 & 28 & 16.7 \\
\hline \multicolumn{11}{|l|}{ Tobacco exposure } \\
\hline Never smoker & 421 & 52.0 & 25 & 5.9 & 254 & 60.3 & 107 & 25.4 & 35 & 8.3 \\
\hline Ex-smoker & 174 & 21.5 & 14 & 8.0 & 113 & 64.9 & 37 & 21.3 & 10 & 5.7 \\
\hline Active smoker & 114 & 14.1 & 4 & 3.5 & 91 & 79.8 & 18 & 15.8 & 1 & 0.9 \\
\hline Passive smoker & 100 & 12.4 & 5 & 5.0 & 56 & 56.0 & 29 & 29.0 & 10 & 10.0 \\
\hline \multicolumn{11}{|l|}{ Asthma severity } \\
\hline Intermittent / Episodic & 215 & 26.6 & 20 & 9.3 & 109 & 50.7 & 64 & 29.8 & 22 & 10.2 \\
\hline Mild / Frequent & 300 & 37.1 & 12 & 4.0 & 203 & 67.7 & 64 & 21.3 & 21 & 7.0 \\
\hline Moderate / Severe & 294 & 36.3 & 16 & 5.4 & 202 & 68.7 & 63 & 21.4 & 13 & 4.4 \\
\hline \multicolumn{11}{|l|}{ Type of physician } \\
\hline Primary care & 553 & 68.4 & 29 & 5.2 & 370 & 66.9 & 113 & 20.4 & 41 & 7.4 \\
\hline \multirow[t]{2}{*}{ Specialist } & 256 & 31.6 & 19 & 7.4 & 144 & 56.3 & 78 & 30.5 & 15 & 5.9 \\
\hline & Mean & SD & Mean & SD & Mean & SD & Mean & SD & Mean & SD \\
\hline Years of evolution & 13.0 & 11.4 & 13.6 & 10.6 & 13.6 & 12.0 & 12.1 & 10.4 & 9.4 & 7.8 \\
\hline
\end{tabular}




\begin{tabular}{|c|c|c|c|c|}
\hline Variables & Category & $\begin{array}{l}\text { Not well- } \\
\text { controlled }\end{array}$ & $\begin{array}{c}\text { Well- } \\
\text { controlled }\end{array}$ & $\begin{array}{c}\text { Totally } \\
\text { controlled }\end{array}$ \\
\hline \multicolumn{5}{|l|}{ Gender } \\
\hline & Male & 0.54 & 0.34 & 0.11 \\
\hline & Female & 0.67 & 0.26 & 0.06 \\
\hline \multicolumn{5}{|c|}{ Type of physician } \\
\hline & Primary Care & 0.68 & 0.23 & 0.09 \\
\hline & Specialist & 0.53 & 0.38 & 0.08 \\
\hline \multicolumn{5}{|c|}{ Age group } \\
\hline & Adults & 0.67 & 0.29 & 0.05 \\
\hline & Children & 0.54 & 0.31 & 0.15 \\
\hline \multicolumn{5}{|c|}{ Asthma severity } \\
\hline & $\begin{array}{l}\text { IIntermittent/ } \\
\text { Occasional Episodic }\end{array}$ & 0.55 & 0.33 & 0.13 \\
\hline & Mild/Frequent Episodic & 0.66 & 0.26 & 0.08 \\
\hline & Moderate / Severe & 0.62 & 0.32 & 0.06 \\
\hline
\end{tabular}

eliminating the effect on the response of complementary variables and compensating for any imbalance.

\section{Results}

829 subjects were recruited, of whom 20 (2\%) were excluded from the analysis because they failed to attend the second study visit or they had missing data in any of the variables included in the model. Therefore, the study population comprised 809 subjects. Subjects' main characteristics are reported in Table 1.

The main analysis assessed the influence of the independent variables on asthma control when the latter was classified as "not well-controlled", "well-controlled" or "totally controlled". Gender (worse control for females, $p=$ 0.003), type of physician (worse control for primary care physicians, $p<0.001$ ), and age group (worse control for adults, $p<0.001)$, were all independently associated with asthma control. At the same time, the interaction between age group and asthma severity was significantly associated with asthma control $(p<0.001)$. Model-adjusted occurrence probabilities (corrected for the possible influence of the rest of variables) of "not well-controlled", "well-controlled" and "totally controlled" asthma, for every category of independent significant factors, are described in Table 2.

Complementary analyses have been performed because asthma severity presented an interaction with age group,
Table 3. Model-adjusted probability of "not well-

controlled", "well-controlled" and "totally controlled"

asthma in every category of the independent significant factors that have an influence on asthma control in adults and children.

\begin{tabular}{|c|c|c|c|c|}
\hline Variables & Category & $\begin{array}{l}\text { Not well- } \\
\text { controlled }\end{array}$ & $\begin{array}{c}\text { Well- } \\
\text { controlled }\end{array}$ & $\begin{array}{c}\text { Totally } \\
\text { controlled }\end{array}$ \\
\hline
\end{tabular}

\begin{tabular}{lllll}
\hline \multicolumn{1}{l}{ ADULTS } & & & \\
\hline Gender & & & & \\
\hline & Male & 0.61 & 0.35 & 0.05 \\
\hline & Female & 0.75 & 0.23 & 0.02
\end{tabular}

\begin{tabular}{llll}
\hline Tobacco exposure & & & \\
\hline Ex-smoker & 0.66 & 0.27 & 0.06 \\
\hline Active smoker & 0.80 & 0.19 & 0.01 \\
\hline Passive smoker & 0.63 & 0.35 & 0.02 \\
\hline Never smoker & 0.61 & 0.33 & 0.06 \\
\hline
\end{tabular}

\begin{tabular}{llll}
\hline Asthma severity & & & \\
\hline Intermittent & 0.50 & 0.44 & 0.07 \\
\hline Mild & 0.73 & 0.25 & 0.02 \\
\hline Moderate / Severe & 0.79 & 0.19 & 0.02 \\
\hline
\end{tabular}

\begin{tabular}{cccc}
\hline Type of physician & & & \\
\hline Primary care & 0.77 & 0.21 & 0.02 \\
\hline Specialist & 0.59 & 0.38 & 0.04 \\
\hline
\end{tabular}

\section{CHILDREN}

\begin{tabular}{rlll}
\hline \multicolumn{1}{l}{ Asthma severity } & & & \\
\hline Ocasional episodic & 0.60 & 0.22 & 0.18 \\
\hline Frequent episodic & 0.57 & 0.22 & 0.22 \\
\hline Moderate / Severe & 0.45 & 0.45 & 0.10 \\
\hline
\end{tabular}

and, moreover, age group could be confounded with tobacco exposure (there were no active smokers in children; $p<0.001$ ) and asthma severity (there were more mild asthmatics among children; $\mathrm{p}<0.01)$. Complementary analyses assessed the influence of independent variables on asthma control when the latter was classified as "not well-controlled", "wellcontrolled" or "totally controlled", stratifying by age group. In adults, a significant association with asthma control was detected for gender $(p=0.001)$, asthma severity $(p<0.001)$, and type of physician $(p<0.001)$, with a borderline effect for tobacco exposure $(p=0.053)$. In children, a significant association with asthma control was found for asthma severity $(p=0.043)$. Probabilities of "not well-controlled", "well-controlled" and "totally controlled" asthma in adults and children, for every category of the independent significant factors, corrected for the influence of the rest of the variables, are described in Table 3. 


\section{Discussion}

According to the results of this analysis, gender, the type of physician who attends the patient, and the patient's age group are significant factors having an influence on asthma control when the analysis is performed on the whole population. In other words, being female, being attended by a primary care physician, or being an adult poses a significantly higher risk of getting "not well-controlled" asthma, as compared with males, patients being attended by specialists, or children.

A significant interaction between age group and asthma severity was detected. This means that the effect of asthma severity on asthma control could differ depending on the age group. A stratified analysis was conducted to explore differential effects based on age groups, not only because of the latter interaction, but because of the lack of active smokers among children - thus making it difficult to interpret correctly the contribution of tobacco in the whole population. On the one hand, gender, asthma severity and the type of attending physician showed a statistically significant influence on asthma control in adults - i.e., being female, suffering from more severe asthma or being attended by a primary care physician posed a significantly higher risk of getting "not well-controlled" asthma for adults. On the other hand, only asthma severity showed a significant influence on asthma control in children, probably due to the smaller sample size of the children subgroup. Compared to adults, children with more severe asthma were less likely to get insufficiently controlled asthma, though they were less likely to get totally controlled asthma too. This might explain the interaction between age group and asthma severity in the whole population.

The results of this analysis confirm to some extent some of the findings published by Prieto et al. ${ }^{4}$ For example, they observed significantly improved asthma control in children and in patients attended by specialists. However, tobacco consumption was found to be a significant factor in the bivariate analyses, since the asthma control profile was worse in active smokers. ${ }^{4}$ This last finding could not be confirmed in our post hoc multivariate analysis, although tobacco exposure showed a nearly-significant effect in adults $(p=0.053)$. Additionally, the multivariate analysis has shown a significant contribution for gender and asthma severity, something which was not detected in the bivariate analyses.

The relation between asthma control and gender, asthma severity, and the type of physician who attends the patient, have already been described in the literature. For example, it has been described that females and a higher degree of asthma severity, among other factors, are both associated with a higher degree of failure to accomplish GINA treatment goals in a cross-sectional study that performed surveys on randomly selected subjects. ${ }^{7}$ In another cross-sectional study performed with 16,580 asthmatic patients in a general practice setting, smoking and age were found to be significant factors influencing the level of asthma control. ${ }^{8}$ Management of asthma by primary care physicians - as compared to specialists - has also been shown to be related to poorer asthma control as measured by the asthma control test (ACT). ${ }^{9}$

It is not clear why women have been consistently shown to suffer from worse asthma control than men. One prospective study performed in patients with severe and/or difficult-to-treat asthma observed a higher prevalence of adult women suffering from this condition than men. ${ }^{10}$ Hormonal differences ${ }^{11}$ or smaller airway calibre ${ }^{12}$ have been addressed as possible factors. In this study, no differences between males and females have been observed in educational level, but other possible confounding factors have not been taken into account (e.g., the level of tobacco exposure or income). However, it is interesting to note that primary care physicians in this study attended a significantly milder profile of adult patients than specialists $(p<0.0001)$ (results not shown). In this regard, possibly the intense attendance pressure on primary care physicians in Spain and, perhaps for some physicians, the lack of necessary training on appropriate asthma management strategies, could be contributing factors for our observation.

Tobacco exposure has been linked with an increased decline in lung function in asthmatic subjects, ${ }^{13}$ with individual parameters of neutrophil inflammation in the airways, ${ }^{14}$ and with asthma morbidity and severity. ${ }^{15}$ Moreover, tobacco consumption has also been associated with development of asthma ${ }^{16}$ although this association has been debated over the last few years. ${ }^{17,18}$ Passive smoking has also been associated with less symptom control and lung function improvement in children with asthma. ${ }^{19}$ In spite of all this, we have not found a statistically significant contribution for tobacco exposure in our study, neither when the analysis was performed in the whole population nor in the agestratified analysis. In our opinion, this could have been due to the absence of active smokers among children, which could have distorted the effect of tobacco exposure in the analysis of the whole population. Interestingly, tobacco exposure showed a borderline effect when adults were analysed separately. In our opinion, had the adult sample sizes have been larger, probably a statistically significant contribution for tobacco exposure would have been shown.

The patient sample in this study was not selected randomly. However, in our opinion, the large sample size and number of centres of the study and the geographical dispersion of the latter lowers the possibility for a selection bias. It is important to clarify, however, that it was not the 
Box. Discussion summary

- Being female, suffering from more severe asthma, or being attended by a primary care physician, poses a statistically significant higher risk of getting "not well-controlled" asthma in adults.

- No significant influence for tobacco has been found, probably because the absence of active smokers among children could have distorted the effect of tobacco exposure in the analysis in the whole population.

- Results from this study address the importance of implementing asthma educational programmes, particularly among general practitioners.

objective of the original study to investigate possible factors related with asthma control. For this reason, the crosssectional nature, and the possible selection bias of this study, these results should be confirmed by additional prospective studies. On the other hand, the relatively small sample size of the children subgroup in our study has probably prevented us from showing additional significant relationship between other independent factors than asthma severity and asthma control in this subgroup of patients. We suggest that future studies investigating factors that contribute to explain asthma control should be performed separating age groups (adults and children) due to the interaction of several explanatory variables with age.

In summary, the results of this exploratory analysis suggest that asthma control can be influenced by gender, age, asthma severity, and the type of physician who attends the patient, after controlling for other variables. These results should be considered in asthma educational programmes and are particularly relevant to general practitioners (GPs). Additional studies are required to look into the influence of these and other factors - such as medical or self-management programmes, or environmental exposure - on asthma control as assessed according to international guidelines.

\section{Conflict of interest}

None to declare.

\section{Funding}

This study has been sponsored by GlaxoSmithKline S.A.

\section{References}

1. Global Strategy for Asthma Management and Prevention. GINA workshop report.
Revised 2006. Avaliable at http://www.ginasthma.org. Accessed May 7, 2007.

2. Rabe KF, Vermeire PA, Soriano JB, Maier WC. Clinical management of asthma in 1999: The Asthma Insights and Reality in Europe (AIRE) study. Eur Respir $J$ 2000;16:802-07. http://dx.doi.org/10.1183/09031936.00.16580200

3. Rickard KA, Stempel DA. Asthma survey demonstrates that the goals of NHLBI have not been accomplished. J Allergy Clin Inmunol 1999;103(1 Pt 2):S171.

4. Prieto L, Badiola C, Villa JR, Plaza V, Molina J, Cimas E. Asthma control: do patients's and physicians' opinions fit in with patients' asthma control status? J Asthma 2007;44:461-7. http://dx.doi.org/10.1080/02770900701421989

5. Bateman ED, Boushey HA, Bousquet J, Busse WW, Clark TJH, Pauwels RA, Pedersen SE for the GOAL investigators group. Can guideline-defined asthma control be achieved? The gaining optimal asthma control study. Am J Respir Crit Care Med 2004; 170:836-44.

6. Global Strategy for Asthma Management and Prevention. GINA Workshop Report. Updated 2003. Available at http://www.ginasthma.org. Accessed October 28, 2004.

7. Soriano JB, Rabe KF, Vermeire PA. Predictors of poor asthma control in European adults. J Asthma 2003;40:803-13. http://dx.doi.org/10.1081/JAS120023572

8. Godard P, Huas D, Sohier B, Pribil C, Boucot I. Asthma control in general practice: A cross-sectional survey of 16,580 patients. Presse Med 2005;34: 1351-7.

9. Laforest L, Van Ganse E, Devouassoux G, et al. Management of asthma in patients supervised by primary care physicians or by specialists. Eur Respir $J$ 2006,27:42-50. http://dx.doi.org/10.1183/09031936.06.00035805

10. Dolan CM, Fraher KE, Bleecker ER, et al. Design and baseline characteristics of The Epidemiology and Natural History of Asthma: Outcomes and Treatment Regimens (TENOR) study: a large cohort of patients with severe or difficult-totreat asthma. Ann Allergy Asthma Immunol 2004;92:32-9.

11. Varraso R, Siroux V, Maccario J, Pin I, Kauffmann F. Asthma severity is associated with body mass index and early menarche in women. Am J Respir Crit Care Med 2005;171:334-39. http://dx.doi.org/10.1164/rccm.200405-6740C

12. Becklake MR, Kauffmann F. Gender differences in airway behaviour over the human life span. Thorax 1999;54:1119-38.

13. Lange P, Parner J, Vestbo J, Schnohr P, Jensen G. A 15 year follow-up study of ventilatory function in adults with asthma. N Eng J Med 1998;339:1194-2000. http://dx.doi.org/10.1056/NEJM199810223391703

14. Chalmers GW, MacLeod KJ, Thomson L, Little SA, McSharry C, Thomson NC. Smoking and airway inflammation in patients with mild asthma. Chest 2001; 120:1917-22. http://dx.doi.org/10.1378/chest.120.6.1917

15. Siroux V, Pin I, Oryszczyn MP, Le Moual N, Kauffmann F. Relationships of active smoking to asthma and asthma severity in the EGEA study. Eur Respir J 2000; 15:470-7. http://dx.doi.org/10.1034/j.1399-3003.2000.15.08.x

16. Piipari R, Jaakkola JJK, Jaakkola N, Jaakkola MS. Smoking and asthma in adults. Eur Respir J 2004;24:734-9. http://dx.doi.org/10.1183/09031936.04.00116903

17. Sandström T, Lundbäck B. Tobacco smoke: old foe more important for asthma than commonly appreciated? Eur Respir J 2004;24:720-1. http://dx.doi.org/10.1183/ 09031936.04.00096804

18. Jindal SK, Gupta D. The relationship between tobacco smoke \& bronchial asthma. Ind J Med Res 2004; 120:443-53.

19. Soussan D, Liard R, Zureik M, Touron D, Rogeaux Y, Neukirch F. Treatment compliance, passive smoking, and asthma control: a three year cohort study. Arch Dis Child 2003;88:229-33. http://dx.doi.org/10.1136/adc.88.3.229

Available online at http://www.thepcrj.org 